\title{
Oral hygiene effects verbal and nonverbal displays of confidence
}

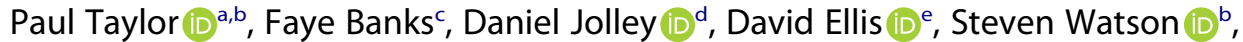 \\ Lynn Weihera ${ }^{a}$ Brittany Davidson (D), and Juliaana Julku ${ }^{\mathrm{c}}$

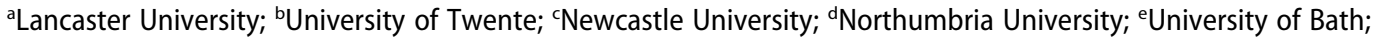 \\ fUniversity of Bristol
}

\begin{abstract}
Although oral hygiene is known to impact self-confidence and self-esteem, little is known about how it influences our interpersonal behavior. Using a wearable, multi-sensor device, we exam ined differences in consumers' individual and interpersonal confidence after they had or had not brushed their teeth. Students $(N=140)$ completed nine one-to-one, 3-minute "speed dating" interactions while wearing a device that records verbal, nonverbal, and mimicry behavior. Half of the participants brushed their teeth using Close-Up toothpaste (Unilever) prior to the interactions, whilst the other half abstained from brushing that morning. Compared to those who had not brushed their teeth, participants who had brushed were more verbally confident (i.e., spoke louder, over-talked more), showed less nonverbal nervousness (i.e., fidgeted less), and were more often perceived as being "someone similar to me." These effects were moderated by attractiveness but not by self-esteem or self-monitoring.
\end{abstract}

\section{ARTICLE HISTORY}

Received 28 July 2018

Accepted 9 June 2020

\section{KEYWORDS}

consumer behavior;

confidence; priming

The oral care market includes products that associate their usage with psycho-social corollaries such as attractiveness, confidence, and being successful. This approach is unsurprising given the positive association of oral health with self-esteem (Macgregor et al., 1997), well-being (Klem et al., 1997), confidence (Dumitrescu et al., 2009), and first impressions (Kershaw et al., 2008). However, these associations relate to studies of the long-term effects of oral health. It remains unknown whether or not an oral care product can bring about an immediate change in consumers' self-esteem or social perception. As we describe below, research suggests this kind of immediate affect is plausible, since breath odor - as one aspect of broader general hygiene - serves both to inform our judgments of others but also our self-perception and its embodiment in behavior (Leary et al., 1995).

Existing research tends to rely on self-report to measure a product's impact. This approach is valuable when the focus is internal perceptions (e.g., self-esteem; cf. Baumeister et al., 2007), but many of the assertions made about oral care products relate to consumers' behavior. In recent years, it has become possible to measure subtle aspects of such behavior using small-scale sensor technologies (Pentland, 2008; Taylor, 2013). Studies have used sensors to identify factors as diverse as social triggers of personality-related aggression (Tomko et al., 2012), the accuracy of self-knowledge (Tenney et al., 2013), and suspects' lying about a past event (Van der Zee et al., 2019). Many of these studies observed differences in behavior that occurred outside of participants' awareness, making these technologies ideal for capturing the subtle changes in behavior promised by oral care products. In this study, we use body worm sensors in a round-robin interaction design that examined changes in individual and interpersonal behavior as a function of having the opportunity to improve personal oral hygiene immediately prior to interaction. 


\section{Oral hygiene and behavior}

Oral hygiene and its manifestation as breath odor is an integral aspect of self-image (Nettleton \& Watson, 1998), which acts as a "danger signal," "boundary maintainer," and implement for "impression management" (Synnott, 1991). For example, McKeown (2003) found that $75 \%$ of patients explained their attendance at a breath odor clinic not with reference to their health but because stale breath had diminished their self-confidence and led them to feel insecure in social relations. Others have also reported breath odor leading to decreased confidence, including reduced self-esteem, increased social anxiety, and the onset of social phobias (Azodo et al., 2010).

The reason why breath odor has a profound impact on confidence is likely to have social roots. Oral hygiene acts as one of a number of social signals that humans use to service their social relationships and social judgments (Dunbar, 1993). We learn to be sensitive to such cues at an early age (e.g., onset of embarrassment; Buss et al., 1979) and they form part of what determines our judgments of others and how we act ourselves (Baron, 1983, 1997). According to the "sociometer hypothesis," a person interprets the inclusionary/exclusionary cues shown by an interaction partner to form a perception of their social position, which then motivates their behavior (Leary et al., 1995). For example, how confidently a person acts within an interaction is a function of whether or not they perceive a need to act confidentially to maintain their social status, as judged from the social cues and their selfevaluation. Such behavior becomes magnified as a person becomes more conscious of the possibility that their poor hygiene is responsible for their experienced status.

A number of studies evidence these effects. For example, in their double-blind study of body odor, Roberts et al. (2009) gave men either a fragrant aerosol spray containing antimicrobial agents (treatment group) or an identical spray containing neither of these active ingredients (control group). After several days, the treatment group reported greater self-confidence and self-perceived attractiveness compared to the control group. Moreover, a female panel who viewed muted video clips of both groups rated participants from the treatment group as more attractive than those from the control group, and their ratings of attractiveness were highly correlated with their ratings of confidence. Thus, the absence of the active spray led participants to behave nonverbally in a way that was perceived as less attractive, arguably because it appeared less "confident."

A similar set of relationships has been shown for verbal behavior. For example, people that have lower trait social anxiety and fear of negative evaluation are more likely to interrupt their conversation partners and preemptively take their turn in the conversation (Natale et al., 1979). Efforts to increase confidence have been shown to attenuate these correlations by having an effect on the associated "confident" behavior (Bogels \& Voncken, 2008). More recently, manipulations of perceived cleanliness have been shown to affect judgments about, and behavior toward, others in a way that suggests an "embodiment" of the stimuli in wider thoughts and behaviors (Xu et al., 2014; cf. Sagioglou \& Greitemeyer, 2014). For example, cleanliness has been shown to reduce both the severity of moral judgments (Schnall et al., 2008) and the kinds of moral and political attitudes that participants report (Helzer \& Pizarro, 2011).

These examples, while not related to oral care directly, allow predictions about how people may react to breath odor. If people intuit that their breath odor will be recognized as a negative marker in an upcoming interaction, then they might become anxious and display this anxiety in their verbal and nonverbal behavior. Such an effect may become magnified when their behavior is compared to a group who have had the opportunity to brush their teeth, since the act of removing the awkward social cue may promote confidence and its associated behaviors (Belmi \& Neale, 2014). Thus, we predict:

H1: Participants who have not cleaned their teeth will show lower nonverbal confidence than those who have cleaned their teeth.

H2: Participants who have not cleaned their teeth will show lower verbal confidence than those who have cleaned their teeth. 


\section{Interpersonal behavior}

So far we have considered how oral hygiene affects the behavior of the individual consumer. However, some products suggest that their use will promote a preferred reaction from the consumer's interaction partner. A product may deliver a functional benefit (e.g., fresh smelling breath) or its use may deliver a psychological benefit (e.g., increased confidence) that changes a person's behavior (e.g., they become more assertive). Both of these scenarios imply that product use may affect interpersonal behavior. That is, the product shapes the behavior of the consumer, which in turn affects the behavior of their interaction partner.

The notion that external sensory stimuli can affect interpersonal behavior is firmly rooted in evolutionary accounts of human social cognition. These argue that aspects of human cognition have evolved to facilitate detection of, and response to, others who may cause us harm, or whose genetic fitness makes them an attractive companion (Schaller, 2008). A growing number of studies have shown that participants will make adverse inferences about a target based on unpleasant or unexpected odors, as well as morphological anomalies, which may once have been symptomatic of parasitic infections (Marinova \& Moss, 2014; Schaller \& Duncan, 2007; Sorokowska, 2013). Such inferences appear to occur even when perceivers know that the anomaly is misleading (Duncan, 2005) or that their response reflects an inappropriate stereotype (Sczesny \& Stahlberg, 2002). Similarly, women show an olfactory preference for the odor of more symmetrical men, especially during their fertile period, suggesting that odor is one of many cues that informs sexual preference (Gangestad \& Thornhill, 1998; Thornhill \& Gangestad, 1999).

While these findings suggest that a person's odors can affect how we judge and act toward them, they say less about how knowledge of these effects may shape personal behavior (i.e., as the sociometer hypothesis predicts) nor how odor will shape behavior in an unfolding interaction. Indeed, there is an absence of research examining the impact of oral care products on partner behavior. In analogous areas, one behavior that has been repeatedly shown to be affected by attraction and willingness to engage is communication accommodation. Communication accommodation refers to the extent to which people adjust their speech, vocal patterns, and gestures to accommodate their interlocutor. When people seek to cooperate, they are sensitive and responsive to the behavior of their partner. Over time, their verbal and nonverbal behavior converges as they accommodate to one another's behavioral patterns (Giles \& Coupland, 1991). This leads them to over-talk and interrupt one another less as they follow the "rules" of turn taking (Hargie, 2014).

Accommodation is driven, in part, by behavioral mimicry, which is the "unconscious or automatic imitation of gestures, behaviors, facial expressions, speech and movements" (p. 2381, Van Baaren et al., 2009). The occurrence of mimicry is often afforded to those who are attractive to self. For example, in two studies, Stel et al. (2010) manipulated the instructions participants received about the confederate they were about to observe in a videoed interaction. These instructions influenced participants a priori liking of the confederate, which in turn affected the degree to which participants mimicked how the confederate's played with their pen, touched their face (Study 1), and their facial expressions (Study 2). Similarly, across two studies, Johnston (2002) showed that participants mimicked the eating behavior of a confederate who was instructed to consume either a lot or little ice cream (i.e., participants monitored the confederate's behavior as a social cue), but they only did so when that confederate did not have a visible social stigma linked to the behavior (i.e., whether or not they were obese).

Johnston's (2002) study is perhaps the closest analog to what we might expect to observe with a manipulation of oral hygiene. It is reasonable to anticipate that Johnston's results could extend to non-visible social stigma such as breath odor, particularly if the odor impacts the way in which the consumer behaves. Thus, the "stigma" of breath odor will lead interaction partners to accommodate the others' behavior less, showing less verbal and nonverbal mimicry of the other partners' behavior than they might otherwise show. We predicted: 
H3: Participants who do not clean their teeth will be interrupted more by their interaction partner compared to participants who do clean their teeth.

H4: Participants who do not clean their teeth will attract less mimicry from their interaction partner compared to participants who do clean their teeth.

\section{Individual differences in effect}

An interesting possibility is that oral hygiene products may be more relevant to sub-groups of the population who are especially concerned with how they appear to others. A number of interrelated constructs, which relate to personal and interpersonal behavior, seek to capture this concern. One is selfesteem, which is both influenced by oral hygiene (Leary \& Terry, 2013) and a moderator of the degree to which people feel confident (Helmreich \& Stapp, 1974) and act confidently (Buhrmester et al., 1988). A second is self-monitoring (Bechierer \& Richard, 1978), which characterizes the extent to which people are concerned with, and act in response to, the impression others have of them, versus acting in ways consistent with their own internal beliefs regardless of social circumstance. Thus, high-self monitors may be more aware of transient personal physiological characteristics, such as oral hygiene, and their reaction may be more extreme as a result. They are also more likely to use the information present in their social environment to adjust their self-presentation, suggesting that they may show greater changes in verbal and nonverbal behavior. We explore these two related individual differences as moderators of behavior in our experiment, investigating in each case whether or not there is a statistically significant interaction between the individual difference and our brushing manipulation.

H5: Those highly conscious of their appearance to others will be more affected by not brushing their teeth than those less conscious of their appearance (i.e., being conscious of appearance will moderate the findings of $\mathrm{H} 1$ through $\mathrm{H} 4$ ).

\section{Method}

\section{Participants}

One-hundred and forty undergraduate and postgraduate students (54 male, 86 female) studying at a UK University were paid $£ 3$ for completing the pre-trial and $£ 12$ for completing the main trial. Their participation in this study was approved by the University's Research Ethics Committee.

\section{Materials}

To measure the impact of individual differences on behavior, we obtained pre-experimental measures of how aware they are of their presentation to others (i.e., self-monitoring), their level of self-esteem, and their attractiveness. We also asked, but do not report here, about participants' self-construal (see Supplementary Materials for analysis).

\section{Self-monitoring}

We used Lennox and Wolfe (1984; see Estow, Jamieson, \& Yates, 2007) Revised Self-Monitoring Scale to measure the degree to which a person is aware of their own presentation and the extent to which this influences others' perception of them (e.g., "I have the ability to control the way I come across to people, depending on the impression I wish to give them"). Participants were required to respond to 13 
statements using a 6-point Likert scale, ranging from 0 (Strongly disagree) to 5 (Strongly agree). The scale showed good reliability (13 items; $\alpha=.760$ ).

\section{Self-esteem}

We used Heatherton and Polivy's (Heatherton \& Polivy, 1991) Current Thought Scale to measure participants' current thoughts about their self-esteem (e.g., "I feel satisfied with the way my body looks right now,"). Participants were required to respond to 20 statement on a Likert scale ranging from 0 (Strongly disagree) to 5 (Strongly agree). Scores on this measure form three sub-scales: performance self-esteem (i.e., related to work performance); social self-esteem (i.e., related to public selfconsciousness); and appearance self-esteem (i.e., related to body image). The measure showed good reliability on the self-esteem $(n=7$ items; $\alpha=.750)$, social self-esteem $(n=7 ; \alpha=.792)$, and appearance self-esteem $(n=6 ; \alpha=.819)$ subscales.

\section{Attractiveness}

To control for the effect of attractiveness on participants' ratings of one another, 46 independent assessors rated each participant's photo. Specifically, each assessor was asked to rate the attractiveness of each participant on a -100 to +100 Visual Analog Scale, where -100 indicated very unattractive and +100 indicated very attractive. The inter-rater reliability of these ratings was extremely high $(\alpha=.976)$.

\section{Procedure}

Figure 1 gives an overview of the research design. Participants were invited to take part in a study on "the social dynamics of brief interactions with strangers." They were asked not to volunteer if under the age of 18 years, pregnant, breastfeeding, undergoing dental treatment, suffering from a condition that prevented normal tooth-brushing, had any form of nasal congestion, or had a known sensitivity or allergy to ingredients listed in the International Nomenclature of Cosmetic Ingredients (INCI) list.

\section{Pre-trial}

Approximately one week prior to the "Speed date interactions" (see Figure 1), participants attended a short pre-trial meeting with a member of the research team. After consenting to take part,

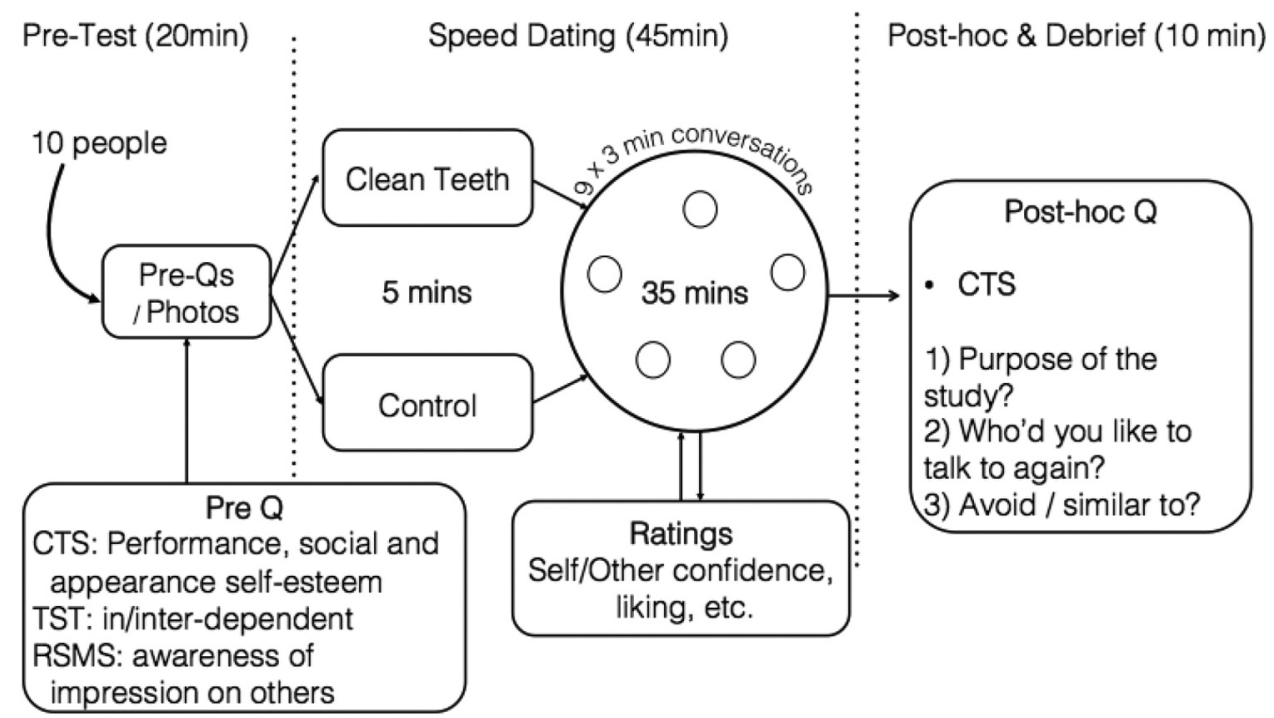

Figure 1. Schematic overview of research design. 
participants posed for a passport-style photo whilst wearing a plain black t-shirt against a plain background. They then completed the self-construal, self-monitoring, and self-esteem measures. On completion, participants were compensated $£ 3$ and given details of the Main trial. They were asked to refrain from eating spicy food, fish dishes, garlic, or drinking tea or coffee within one hour before the Main trial. They were also asked to not clean their teeth the morning of the Main trial, which occurred at 9:45am, and reminded to not take part if they were pregnant or allergic to any ingredient on our INCI list.

\section{Main trial}

Participants attended the trial in groups of ten. On arrival, they were given a badge denoting a letter and they were seated apart to minimize pre-trial mingling. Once all participants had arrived, a researcher explained that they would be completing a series of 3-minute, one-to-one interactions (i.e., "rounds"), in a similar fashion to speed dating, with the aim of "getting to know one another." They were told that they would need to wear a black t-shirt to standardize their appearance in the interactions. In reality, as well as standardizing appearance, requiring $\mathrm{t}$-shirts provided a method for separating participants for the experimental manipulation. Specifically, participants were randomly assigned to a control or experimental group, each of which contained five participants with a mixture of males and females. Each group of five participants was instructed to follow a researcher to one of two, multi-cubical bathrooms to put on a black t-shirt in private. The use of two bathrooms was explained as a way to speed up the process of putting on the t-shirts. However, whilst in the bathroom, those randomized to the "experimental" bathroom also cleaned their teeth using Close-Up toothpaste (Unilever). A researcher timed participants' cleaning their teeth for one minute using a stopwatch. These participants were not instructed to not mention the brushing; we did not want to raise suspicion about the manipulation. For the same reason, we did not ask participants to confirm that they had followed our pre-trial instructions to not eat particular food groups and not brush their teeth that morning. Instead, we used a set of post-trial checks (described below) to ascertain the extent to which participants guessed the manipulation.

After the manipulation, pairs of participants were directed to stand at one of five tables, where they were also each given a sociometric badge, an instruction sheet, and a questionnaire pack. The instruction sheet indicated the table to which each participant should move following each 3-minute interaction round. This ensured that every participant spoke to every other participant. The questionnaire pack contained a set of post-interaction questions that participants completed immediately after each round. The questions required participants to rate, on an 8-point scale, the degree to which they felt "nervous vs. relaxed" and "confident vs. unconfident." It also asked their perception of the degree to which their partner felt "nervous vs. relaxed," confident vs. unconfident," and "like me vs. different from me." Finally, it asked them to report how well they knew the person prior to the interaction. This latter question sought to control for the possibility that some participants may be acquainted.

Once each item on the instruction sheet had been explained, participants were shown how to wear and switch on their sociometric badge. They were also familiarized with the sound of the bell, which would signal the start and end of each round. The series of interactions then began with participants working through iterations of talking to their partner for 3-minutes, completing a set of questions about the interaction, and moving to the next table as indicated on their instruction sheet, in order to begin the next round. After the final round, participants were asked to independently complete an experimental booklet, which included the Current Thoughts Scale (Heatherton \& Polivy, 1991) as our measure of self-esteem and four post-hoc questions: i) Who would you like to talk to again?; ii) Who is most similar to you?; iii) Who would you like to avoid in the future?; and, iv) What did you think was the purpose of this study? For the first three questions, participants were asked to indicate their 'top-3' ranking (i.e., the three people who they identified for the question).

On completing the questionnaire packs, participants were asked to switch off and remove their sociometric badge and take off the black $\mathrm{t}$-shirts. At this point a researcher debriefed the participants on 
the nature of the study and the toothpaste manipulation. The participants were then invited to enjoy a free continental breakfast and given $\mathfrak{E 1 2}$ for their participation. Participants who had not cleaned their teeth were also given the opportunity to do so using a toothbrush and toothpaste that we provided.

\section{Measuring behavior through social sensors}

Capitalizing on recent developments in wearable sensor technology, we measured participants' social behavior by having each wear a sociometric sensor (Choudhury \& Pentland, 2000). A sociometric sensor is a small cigarette-box sized device that is worn around the neck in the same way as a lanyard. It measures individual and interpersonal behaviors by way of four sensors: i) a microphone that records speech; ii) an accelerometer that measures the degree and direction of movement; iii) a Bluetooth transmitter that measures the proximity of multiple sensors; and, iv) an infrared transmitter that measures when two sensors (i.e., sensor wearers) are facing one another. Once activated, the sensors provide a time-synchronized recording of the sensor outputs at a minimum of one per second.

\section{Dependent variables}

The data recorded from the four sensors can be translated into useful measures of social behavior (see Olguin Olguin et al., 2009, for a review). We focused on two pairs of measures relevant to our hypotheses. For verbal confidence, we focused on participants' assertiveness and participants' speech accommodation. We used speech volume as a marker of individual assertiveness (Page \& Balloun, 1978), measured as mean speech volume modulation per minute by the badge's onboard microphones and band-pass filters. We used speech overlap (i.e., the degree to which a participant speaks at the same time as their partner) as a marker of accommodation, measured by cross-comparing the microphone data to derive an average count per millisecond in which both the participant and their partner were both talking. This approach is modeled on Kim et al. (2008), who found these data allowed the identification of who amongst a group of badge wearers was dominant within the interaction.

In relation to nonverbal confidence, we focused on participants' body movement and their movement mimicry. Previous work has shown that less overall body movement is associated with lower stress (Yano et al., 2009) lower social anxiety (Schlenker \& Weigold, 1992), and perceptions of confidence (Ambady \& Rosenthal, 1993). We measured body movement using the acceleration signal vector magnitude derived from changes in each axis of the sensor's 3-axis accelerometer (Olguin Olguin et al., 2009). Our focus on movement mimicry sought to measure the degree to which movements by one actor were replicated by similar degrees of movement by the other actor (Kim et al., 2008). We measured mimicry by using a cross-comparison of the body movement scores to derive a single correlation that reflected the similarity of movement. This measure is modeled on Kalimeri et al.'s (2011) work, which demonstrated the importance of considering relative movement between interactants when measuring confidence and social influence.

Although our mimicry measure has been used in previous studies successfully (Kim et al., 2008; Parker et al., in press), we assessed its relationship to mimicry as perceived by human observers. We had three independent coders (the coders were blind to the study hypotheses but familiar with nonverbal mimicry) rate the degree of mimicry for participants across 11 sessions. Each session was video recorded (no audio), and coders were asked to rate interactions on a scale from 1 (no evidence of mimicry) to 9 (significant mimicry). The coding of mimicry showed a positive but negligible correlation with our body movement measure of mimicry, Mean $r=.088$, Range: $-.063-.222$, and our measure of posture mimicry, $r=.084$, Range: $.025-.164$ (note: the coder scored only overall mimicry and did not assess posture mimicry separately). This finding is consistent with other comparisons of subjective and objective interaction synchrony measures (Nelson et al., 2016). As recognized by Ramseyer and Tschacher (2011), objective measures such as ours are limited to measuring dynamic synchrony (i.e., coordination of movement), thereby overlooking both the "static" mirroring of specific gestures and the subjective impression of 
holistic synchrony that judges may use to guide their coding. Consistent with this possibility, we observed a significant relationship between the coder's ratings and postural movement, Mean $r=.195$, Range: $.100-.265$, implying that their judgments were in part related to participants' movements in a way not apparent to the sociometric badges.

\section{Results}

Although 140 students took part in the trial, data from 8 participants were excluded due to technical failure of the sociometric sensors and data from 1 participant was excluded because they did not meet the volunteering criteria. During the post-hoc questionnaire, 6 of the 131 participants reported suspecting that the study was interested in the effect of teeth cleaning on communication. As this represents a small percentage of the total sample, and because no participant explicitly identified the manipulation of toothpaste users and non-users, all participants were included in the analyzes. Thus, the final sample size was 131. (We report in Supplementary Materials Table 4 all our analyzes with these six participants removed. All the main effects and interactions remained the same with the exception of the secondary analyzis of postural movement for $\mathrm{H} 1$, which changed from a significant to non-significant effect. This change is noted below). Our data and materials are openly available at https://dx.doi.org/10.17635/lancaster/researchdata/361.

\section{Manipulation check}

To determine whether or not variation in participants' behavior was associated with differences in confidence, we examined participants' self-report as a function of the brushing manipulation. A linear model in which confidence ratings made after each interaction were examined across brushing condition while controlling for the repeated observations from each participant, found that participants reported significantly higher confidence when they had used toothpaste $(M=3.48 ; S D=1.77)$ compared to when they had not $(M=3.17 ; S D=1.80), F(1,1043)=5.14, p=.024, d=0.40,95 \% \mathrm{CI}$ $[0.05,0.75]$. This finding is complemented by participants' nervousness ratings, with those who used toothpaste $(M=5.42 ; S D=1.44)$ reporting lower nervousness than those who had not $(M=5.63$; $S E=1.30), F(1,1043)=26.50, p<.001, d=0.90,95 \%$ CI $[0.54,1.26]$.

An interesting possibility raised by the general sociometer hypothesis (Leary et al., 1995) is that participants' feelings became magnified over time as they become more conscious of their oral hygiene. An analysis of the two self-report scores as a function of interaction round and brushing manipulation revealed a non-significant decrease in confidence over rounds $\left(M_{\text {Round1 }}=3.48\right.$, $S D=1.38$, to $\left.M_{\text {Round } 9}=2.97, S D=1.92\right), F(8,1009)=1.46, p=.168, d=0.43,95 \% \mathrm{CI}[-0.27,1.13]$, and a significant increase in nervousness over rounds $\left(M_{\text {Round } 1}=5.02, S D=1.32\right.$, to $M_{\text {Round } 9}=6.04$, $S D=1.23) F(8,1009)=2.82, p=.004, d=.60,95 \% \mathrm{CI}[-0.10,1.29]$. However, neither of these changes in self-response over time interacted with brushing condition (both $F$ s $<1$ ).

Finally, there was no statistically significant difference in the attractiveness ratings between participants who used toothpaste $(M=-3.67, S D=24.25)$ and those who did not $(M=3.76$, $S D=21.53), t(129)=-.021, p=.98$.

\section{Subjective preference}

We examined the degree to which participants showed a preference in their post-experiment responses toward those who had brushed over those who had not. This served as a useful comparison to previous research because it mirrors the preferences expressed by consumers in other forms of product development (e.g., opinion groups). Participants' ranking of responses to the "see again", "similarity", and "avoidance" questions were scored in terms of whether they referred to somebody who had cleaned their teeth (scored as 1.00) versus someone who had not (scored as -1.00 ). Thus, a mean ranking above .00 would indicate that participants selected on average participants who had 
cleaned their teeth, while a mean ranking below .00 would indicate that participants on average selected those who had not cleaned their teeth. Participants' preferences could then be tested with a one-sample t-test comparison against no preference (i.e., zero).

Participants reported no significant preference for "wishing to talk to again" those who had brushed over those who had not brushed, $(M=-.059, S D=.527), t(129)=-1.28, p=.205, d=.112,95 \% \mathrm{CI}$ $[-.29, .06]$. Nor did they express a significant preference toward not choosing those who had brushed as "someone I would prefer to avoid" compared to those who had not brushed, $(M=.095, S D=.574), t$ $(118)=1.81 p=.073, d=.166,95 \%$ CI $[-.02, .35]$. They did, however, rate those who had brushed as being most similar to them than those who had not brushed, when they themselves had not brushed $(M=.25, S D=.976), t(63)=2.049, p=.045, d=.256,95 \% \mathrm{CI}[.01, .51]$, but not when they had brushed $(M=-.19, S D=.990), t(63)=-1.52, p=.135, d=.192,95 \%$ CI $[-.44, .06]$.

\section{Hypothesis tests}

To test our hypotheses, we used linear mixed-effects regression in R (LMER; Bates et al., 2014) to enable us to model the variance associated with repeated interactions (i.e., each participant took part in nine interactions), partner differences (i.e., the extent a participant's behavior was the result of their partner's unique behavior), and dyad interdependence, without data aggregation (Judd et al., 2012). To do so, we employed regressions that modeled as random effects the interdependence of dyad observations (i.e., 1 | dyad.number) and the variation in partner's behavioral contribution, in which we nested our participants (i.e., 1 | partner.number/participant.number). Since dyads were unique to testing sessions, this approach also captured effect across testing session (an assumption we checked by re-modeling with dyad nested in session, which obtained the same results as reported below but with variations at the second decimal place).

Our testing approach thus draws on the principles put forward in the social relations modeling literature (Kenny \& Kashy, 2011; Snijders \& Kenny, 1999) and proponents of dyadic data analysis in particular (Knight \& Humphrey, 2019). Since we do not specifically manipulate group-level effects (i.e., there is no block design), we used the dyad as our unit of analysis, while ensuring we modeled the interdependencies across dyads that stem from individual differences in behavior. Consistent with the approach of others (Chetverikov \& Filippova, 2014), we focused on the factor effects for the brushing manipulation and report these using Wald $F$ tests (Type 3) with a Kenward-Roger degrees of freedom approximation. The Means and SEs for body movement reported below are multiplied by 1000 to facilitate presentation. We report $p$-values with our testing but encourage the reader to interpret these cautiously, both because they are estimated parameters (Kenward \& Roger, 1997) and because our data structure involves a set of repeated measures that limits the independence of our observations.

\section{Individual behavior}

To test our prediction (H1) that brushing would reduce displays of nervous behavior, we examined body movement as a function of treatment condition. Those who had brushed moved less $(M=8.05$, $S E=.174)$ than those who had not $(M=8.91, S E=.169), F(1,874.8)=14.46, p<.001, d=0.76,95 \% \mathrm{CI}$ $[0.37,1.14]$. The effect was not moderated by attractiveness, $F(1,929.2)=2.80, p=.09$. The data from the sociometric badges enabled the amount of postural shift to be disaggregated from total body movement by considering the absolute angular velocity for a badge at every time point. An equivalent analysis using posture activity as the Dependent Variable revealed that those who had brushed showed less postural movement $(M=3.19, S E=.092)$ than those who had not $(M=3.38, S E=.091), F(1$, $927.6)=3.96, p=.047, d=0.23,95 \%$ CI $[0.003,0.45]$, and that this was not moderated by attractiveness $(F<1)$. This effect was not significant when our analyzes excluded the six participants who expressed some awareness of the experiment's purpose (see Supplementary Materials, Table 4). Thus, there is only tentative evidence to suggest that the significant differences in overall body movement across conditions manifests, in part, as differences in postural "engagement." 
To test our hypothesis that brushing will lead participants to be more verbally assertive (H2), we examined speech volume as a function of treatment condition. There was a significant condition $\mathrm{x}$ attractiveness interaction, $F(1,743.9)=9.77, p=.002$, suggesting that there was an effect of brushing on speech volume, but this was a function of participant attractiveness. A simple slopes analysis revealed that participants rated by others as low in attractiveness $(-1 \mathrm{SD})$ were significantly louder when they had brushed compared to when they had not brushed $(M=.05$ vs. -.41$), t(134)=2.89$, $p=.005, r=.23$. This difference was not significant for participants rated by others as high in attractiveness (+1SD; $M=-.14$ vs. .06), $t(134)=-1.27, p=.207, r=-.10$.

\section{Partner effects}

To test our prediction that brushing will show interpersonal dominance by talking-over their interaction partner (H3), we examined the degree of overlapping speech as a function of condition, while accounting for participant-partner interdependence and attractiveness. This revealed a statistically significant three-way interaction between participant brushing, partner brushing, and attractiveness, $F$ $(1,820.0)=6.51, p=.011$. When interacting with partners who had not brushed, participants showed a non-significant tendency to increase over-talk irrespective of their attractiveness $(M=-.027$ vs. $M=.028)$. When interacting with partners who had brushed, participants low in attractiveness $(-1 \mathrm{SD})$ over-talked significantly more when they had brushed compared to when they had not $(M=.23$ vs. $-.48), t(494)=2.76, p=.006, r=.357$. Participants high in attractiveness $(+1 \mathrm{SD})$ showed no difference across treatment $(M=.25$ vs. -.16$), t(494)=-1.53, p=.128, r=-.204$.

To test our hypothesis that increased confidence will manifest as greater interpersonal influence within interactions ( $\mathrm{H} 4)$, as measured by mimicry, we examined the degree of movement mimicry shown by participants and their partners while controlling for participant and partner interdependence and attractiveness. An examination of mimicry using the overall body movement measure described above revealed no effect of treatment, $F<1$, and no higher form of interaction between participant-partner condition or with attractiveness. An analysis using posture mimicry, however, did reveal non-significant relationships consistent with our prediction. Participants who had brushed tended to have their posture mimicked more than participants who had not brushed, though this effect showed some evidence of being dependent on participant attractiveness, $F(1,601.2)=2.86, p=.091$. A simple slopes analysis suggested that the manipulation of brushing had a larger effect on mimicry for those low in attractiveness $(M=.19$ vs. -.43$), t(134)=1.82, p=.071, r=.030$, compared to those high in attractiveness $(M=-.013$ vs. .028$), t(134)=-1.28, p=.202, r=-.021$.

\section{Individual differences}

To test our prediction of individual differences in responsiveness to brushing (H5), each of the analyzes presented above were repeated with the two individual difference measures as covariates. Overall there were no significant effects of self-esteem or self-monitoring on participants' behavior. This is not untypical of behavior that is largely outside of conscious control.

\section{Discussion}

Across verbal and nonverbal measures, a predictable pattern emerged in participants' behavior after brushing or not brushing their teeth. Compared to those who did not brush, those who brushed their teeth showed less body movement $(\mathrm{H} 1)$ and greater verbal assertiveness ( $\mathrm{H} 2$, and $\mathrm{H} 3$ for those rated low on attractiveness) in their interactions with others. These differences in behavior suggest that using toothpaste led participants to behave in ways that are typically associated with greater selfconfidence. Indeed, this is what participants reported as their subjective experience. Toothpaste users self-reported being more confident and less nervous than those who had not used toothpaste. The manipulation also had meaningful interpersonal effects, to the point of changing the subjective 
impression of the partner. Users of toothpaste were selected as the person "who is most similar to me" more than might be expected by chance.

These findings offer tentative evidence that oral hygiene can influence behavior in the short term, thereby building on evidence of associations between oral hygiene and a person's perceptions and selfconfidence (Macgregor et al., 1997). The results resonate with related research, such as studies showing a positive correlation between subjective confidence and speech volume (Kimble \& Seigel, 1991) and interruptions (Natale et al., 1979). Similarly, recent work on deception has shown that nervous liars showed greater body movement than truth-tellers (Van der Zee et al., 2019), while work on rapport suggests that positivity (e.g., head nodding, forward lean) is associated with early efforts to generate rapport (as we found in our non-toothpaste users) (Tickle-Degnen \& Rosenthal, 1990). Given this consistency with previous work, and participants subjective reporting, we can place some certainty in our interpretation that the changes in behavior reflect a differential in confidence after participants brushed their teeth. While changes in vocal behavior might be attributed to having a stale or fresh mouth, changes in nonverbal behavior cannot easily be explained by such a direct association.

While this explanation is promising, further evidence is needed before we conclude an association between oral hygiene and interpersonal confidence. One reason for this caution is statistical. Our round-robin design afforded more points of comparison than a between-subjects design, but its complexity means that our $p$-values should be interpreted carefully. They are based on degrees of freedom estimates that are likely inflated by the fact that each participant is responsible for nine observations. Our modeling is likely to have ensured that the effects are estimated well, but the $p$-values associated with them will be less reliable because of all the repeated observations.

A second reason for caution is methodological. Our participants were asked to refrain from normal morning ritual behaviors, such as brushing their teeth or grabbing a coffee. While we carefully implemented the study to give participants the impression that our requests, including to wear a black t-shirt, were designed to standardize their appearance, and while only a few participants guessed that teeth brushing was a manipulation, it would be naive to assume our instructions had no effect. It is possible, for example, that some participants did not comply with our requests fully, or that the change in routine affected their behavior by increasing self-awareness, or even that brushing gave a sense of "reward" not afforded to those in the non-brushing condition. Each of these possibilities may act to moderate or mediate the association between oral hygiene and behavior.

Some insights into how participants perceived the experiment were provided by the subjective measures. One curious result was the increase in self-reported nervousness over the nine interactions, which occurred regardless of whether or not participants had brushed their teeth. This is arguably the opposite of what might be expected to occur under the assumption that participants would relax and "get into" the interactions over time. The increase in nervousness suggests some un-measured factors led to more self-conscientiousness over time, perhaps even related to other hygiene issues (e.g., they all became hot and sweaty over time). Critically, however, the absence of an interaction with the brushing manipulation suggests this increased nervousness was not a result of half of the participants realizing the other half had brushed their teeth.

A second pattern in the data that touches on perceptions pertains to the effects observed for attractiveness, which did not occur for self-esteem or self-monitoring. In general, participants rated as lower on attractiveness showed greater differences in behavior across the toothpaste manipulation (H5). This result may tentatively suggest that self-awareness regarding personal attractiveness may moderate the effects of hygiene. Specifically, those who have learned from experience that others perceive them as attractive may be less concerned by not brushing their teeth, while those who are selfaware of others' perceptions may extend this concern to their current state of oral hygiene.

Overall the data produced by the sociometric badges provided a set of explainable findings that are consistent with evidence published in other areas using alternative methodologies. This suggests that the device will make a compelling addition to the methods used in product development and evaluation. It may be particularly useful because, as our analysis of behaviors associated with nervousness shows, the badge is able to capture elements of behavior that are typically expressed nonverbally. While our round-robin design allowed us to also capture participants' relative 
nervousness ratings, these subjective data would be more difficult to decipher in simple research designs; thus, it is in this context that the sociometric badge may prove particularly valuable. The extent of its value will depend on the influence of social signaling relative to contextual factors, such as clothing, that moderate first impressions. Our participants did not have access to cues that may play a primary role in social choice (e.g., clothing choice; Grammer et al., 2004), and they had no choice in their interaction partners. All of these factors may reduce or magnify the effects observed in this study, which may be critical given the small effect sizes.

In relation to these moderators, it is also important to acknowledge that the longer-term effects associated with oral hygiene are also unclear from the current study. For example, did the effects of brushing persist throughout the day after the experiment? Did any of the participants stay in touch after the study, and was this more likely for participants who brushed their teeth? Such effects could be investigated through a longitudinal study design with periodic follow-up assessments allowing for the measurement of consumer behavior over time. However, doing so would be a challenge because of the difficulty of controlling usage and other factors that may influence behavior. Alongside this, it will also be important to consider the relative impact of different types of products and general hygiene, since doing so may help illuminate the reasons why brushing has the effects it does. It will be interesting, for example, to determine whether it is the act of brushing, the embodiment of freshness, or some other social dynamic that is the driver of users' changing behavior. From a product development perspective, the sociometric badge may provide a variety of behavioral markers that are equivalent to people's experiences of a product. Across a variety of contexts, these will allow producers to make business decisions about their products based on differences that have significant effects on consumer experience and behavior.

\section{Data availability statement}

The data described in this article are openly available in the Open Science Framework at 10.17635/lancaster/research data/361

\section{Disclosure statement}

No potential conflict of interest was reported by the authors.

\section{Funding}

This project was funded by Unilever grant (MA-2014-01966). Unilever provided the toothpaste and toothbrushes but remained independent from the experimental design, data collection, or data analysis and interpretation.

\section{Notes on contributors}

Paul J. Taylor received a PhD in Psychology from the University of Liverpool, UK. He is now Professor of Psychology at Lancaster University, UK, and a Professor of Human Interaction at the University of Twente, NL.

Faye Banks received her PhD from the Spectrum Centre for Mental Health Research at Lancaster University. She is now undertaking her Clinical Doctorate at Newcastle University, UK.

Daniel Jolley received a $\mathrm{PhD}$ in Social Psychology from the University of Kent. He is currently a Senior Lecturer at Northumbria University, UK.

David A. Ellis received a PhD in Psychology from the University of Glasgow, UK. He is now an Associate Professor in Information Systems at the University of Bath, UK.

Steven J. Watson received his $\mathrm{PhD}$ from the University of East Anglia in 2013, and having worked as a post-doc at Lancaster and Lecturer in Forensic Psychology at Newcastle, now works as an Assistant Professor in Psychology at the University of Twente, NL. He mostly researches in investigative and security psychology.

Lynn Weiher received her MSc in Forensic Psychology from the University of Maastricht and is now undertaking a PhD in Psychology at Lancaster University, UK. 
Brittany I. Davidson received a $\mathrm{PhD}$ in Information Systems from the University of Bath. She is now a post-doc researcher in Digital Health Engineering at the University of Bristol, UK, where her work focuses on mental health service engagement of young people. Her other work uses big data analytics and text mining to better understand technology usage patterns.

Juliaana Julku received her BSc in Psychology from Newcastle University this year.

\section{ORCID}

Paul Taylor (iD http://orcid.org/0000-0001-8743-7667

Daniel Jolley (iD http://orcid.org/0000-0001-7232-8599

David Ellis (iD http://orcid.org/0000-0001-6172-3323

Steven Watson iD http://orcid.org/0000-0002-9042-2391

Brittany Davidson (iD) http://orcid.org/0000-0001-9886-9043

\section{Open Scholarship}

\section{(11) 장}

This article has earned the Center for Open Science badge for Open Data and Open Materials. The data and materials are openly accessible at 10.17635/lancaster/researchdata/361

\section{References}

Ambady, N., \& Rosenthal, R. (1993). Half a minute: Predicting teacher evaluations from thin slices of nonverbal behavior and physical attractiveness. Journal of Personality and Social Psychology, 64(3), 431-441. https://doi.org/10.1037/ 0022-3514.64.3.431

Azodo, C. C., Osazuwa-Peters, N., \& Omili, M. (2010). Psychological and social impacts of halitosis: A review. Journal of Social and Psychological Sciences, 3(1), 74-92. https://www.researchgate.net/publication/ 339229281_Psychological_and_Social_impact_of_halitosis_A_review

Baron, R. A. (1983). Sweet smell of success? The impact of pleasant artificial scents on evaluations of job applicants. Journal of Applied Psychology, 68(4), 709-713. https://doi.org/10.1037/0021-9010.68.4.709

Baron, R. A. (1997). The sweet smell of ... helping: Effects of pleasant ambient fragrance on prosocial behavior in shopping malls. Personality and Social Psychology Bulletin, 23(5), 498-503. https://doi.org/10.1177/0146167297235005

Bates, D., Maechler, M., Boker, B., \& Walker, S. (2014). lme4: Linear mixed-effects models using eigen and S4. R package version.

Baumeister, R. F., Vohs, K. D., \& Funder, D. C. (2007). Psychology as the science of self-reports and finger movements: Whatever happened to actual behavior? Perspectives on Psychological Science, 2(4), 396-403. https://doi.org/10.1111/j. 1745-6916.2007.00051.x

Bechierer, R. C., \& Richard, L. M. (1978). Self-monitoring as a moderating variable in consumer behavior. Journal of Consumer Research, 5(3), 159-162. https://doi.org/http://dx.doi.10.1086

Belmi, P., \& Neale, M. (2014). Mirror, mirror on the wall, who's the fairest of them all? Thinking that one is attractive increases the tendency to support inequality. Organizational Behavior and Human Decision Processes, 124(2), 133-149. https://doi.org/10.1016/j.obhdp.2014.03.002

Bogels, S. M., \& Voncken, M. (2008). Social skills training versus cognitive therapy for social anxiety disorder characterized by fear of blushing, trembling or sweating. Interpersonal Journal of Cognitive Therapy, 1(2), 138-150. https://doi.org/10.1521/ijct.2008.1.2.138

Buhrmester, D., Furman, W., Wittenberg, M. T., \& Reis, H. T. (1988). Five domains of interpersonal competence in peer relationships. Journal of Personality and Social Psychology, 55(6), 991-1008. https://doi.org/10.1037/0022-3514.55.6.991

Buss, A. H., Iscoe, I., \& Buss, E. H. (1979). The development of embarrassment. Journal of Psychology: Interdisciplinary and Applied, 103(2), 227-230. https://psycnet.apa.org/record/1981-01091-001

Chetverikov, A., \& Filippova, M. (2014). How to tell a wife from a hat: Affective feedback in perceptual categorization. Acta Psychologica, 151(1), 206-213. https://doi.org/10.1016/j.actpsy.2014.06.012

Choudhury, T., \& Pentland, A. (2000) The sociometer: A wearable device for understanding human networks. Proceedings of computer supported cooperative work. New Orleans, LA. 
Dumitrescu, A. L., Dogaru, B. C., \& Dogaru, C. D. (2009). Self-control and self-confidence: Their relationship to self-related oral health status and behaviours. Oral Health \& Preventive Dentistry, 7(1), 155-162. PMID: 19583041. https://pubmed.ncbi.nlm.nih.gov/19583041/

Dunbar, R. (1993). Coevolution of neocortical size, group size and language in humans. Behavioral and Brain Sciences, 16(4), 681-694. https://doi.org/10.1017/S0140525X00032325

Duncan, L. A. (2005). Heuristic cues automatically activate disease cognitions despite rational knowledge to the contrary (Unpublished MA thesis), University of British Columbia.

Estow, S., Jamieson, J. P., \& Yates, J. R. (2007). Self-monitoring and mimicry of positive and negative social behaviors. Journal of Research in Personality, 41(2), 425-433. https://doi.org/10.1016/j.jrp.2006.05.003

Gangestad, S. W., \& Thornhill, R. (1998). Menstrual cycle variation in women's preference for the scent of symmetrical men. Proceedings of the royal society of London B, 262(1399), 727-733. https://doi.org/10.1098/rspb.1998.0380

Giles, H., \& Coupland, N. (1991). Accommodating language: Contexts and consequences. Open University Press.

Grammer, K., Renninger, L., \& Fischer, B. (2004). Disco clothing, female sexual motivation, and relationship status: Is she dressed to impress? Journal of Sex Research, 41(1), 66-74. https://doi.org/10.1080/00224490409552214

Hargie, O. (2014). Communication accommodation in a divided society: Interaction patterns between protestants and catholics in Northern Ireland. Studies in Communication Sciences, 14(1), 78-85. https://doi.org/10.1016/j.scoms.2014.03.005

Heatherton, T. F., \& Polivy, J. (1991). Development and validation of a scale for measuring state self-esteem. Journal of Personality and Social Psychology, 60(6), 895-910. https://doi.org/10.1037/0022-3514.60.6.895

Helmreich, R., \& Stapp, J. (1974). Short forms of the Texas social behavior inventory (TSBI), an objective measure of self-esteem. Bulletin of the Psychonomic Society, 4(5), 473-475. https://doi.org/10.3758/BF03334260

Helzer, E. G., \& Pizarro, D. A. (2011). Dirty liberals!: Reminders of physical cleanliness influence moral and political attitudes. Psychological Science, 22(4), 517-522. https://doi.org/10.1177/0956797611402514

Johnston, L. (2002). Behavioral mimicry and stigmatization. Social Cognition, 20(1), 18-35. https://doi.org/10.1521/soco. 20.1.18.20944

Judd, C. M., Westfall, J., \& Kenny, D. (2012). Treating stimuli as a random factor in social psychology: A new and comprehensive solution to a pervasive but largely ignored problem. Journal of Personality and Social Psychology, 103 (1), 54-69. https://doi.org/10.1037/a0028347

Kalimeri, K., Lepri, B., Kim, T., Pianesi, F., \& Pentland, A. (2011). Automatic modeling of dominance effects using granger causality. Human Behavior Understanding, 7065, 124-133. https://doi.org/10.1007/978-3-642-25446-8_14

Kenny, D. A., \& Kashy, D. A. (2011). Dyadic data analysis using multilevel modeling. In J. Hox \& J. K. Roberts (Eds.), Handbook of advanced multilevel analysis (pp. 344-360). NY Guilford Press.

Kenward, M. G., \& Roger, J. H. (1997). Small sample inference for fixed effects from restricted maximum likelihood. Biometrics, 53(3), 983-997. https://doi.org/10.2307/2533558

Kershaw, S., Newton, J. T., \& Williams, D. M. (2008). The influence of tooth colour on the perceptions of personal characteristics among female dental patients: Comparisons of unmodified, decayed and 'whitened' teeth. British Dental Journal, 8(E9), 204. https://doi.org/10.1038/bdj.2008.134

Kim, T., Chang, A., Holland, L., \& Pentland, A. (2008). Meeting mediator: Enhancing group collaboration with sociometric feedback. Proceedings of the 2008 ACM conference on computer supported cooperative work (pp. 457-466).

Kimble, C. E., \& Seigel, S. D. (1991). Vocal signs of confidence. Journal of Nonverbal Behavior, 15(2), 99-105. https://doi. org/http://dx.doi.10.1007

Klem, M. L., Wing, R. R., McGuire, M. T., Seagle, H. M., \& Hill, J. O. (1997). A descriptive study of individuals successful at long-term maintenance of substantial weight loss. The American Journal of Clinical Nutrition, 66(2), $239-246$. https://doi.org/10.1093/ajcn/66.2.239

Knight, A. P., \& Humphrey, S. E. (2019). Dyadic data analysis. In S. Humphrey \& J. M. LeBreton (Eds.), The handbook of multilevel theory, measurement, and analysis (pp. 423-447). American Psychological Association.

Leary, M. R., \& Terry, M. L. (2013). Self-evaluation and self-esteem. In D. Carlston (Ed.), Oxford handbook of social cognition (pp. 534-547). Oxford University.

Leary, M. R., Tambor, E. S., Terdal, S. K., \& Downs, D. L. (1995). Self-esteem as an interpersonal monitor: The sociometer hypothesis. Journal of Personality and Social Psychology, 68(3), 518-530. https://doi.org/10.1037/00223514.68.3.518

Lennox, R. D., \& Wolfe, R. N. (1984). Revision of the self-monitoring scale. Journal of Personality and Social Psychology, 46(6), 1349-1364. https://doi.org/10.1037/0022-3514.46.6.1349

Macgregor, I. D. M., Regis, D., \& Balding, J. (1997). Self-concept and dental health behaviours in adolescents. Journal of Clinical Periodontology, 24(5), 335-339. https://doi.org/10.1111/j.1600-051X.1997.tb00766.x

Marinova, R., \& Moss, M. (2014). The smell of success? The impact of perfume-gender congruency on ratings of attraction and the halo effect. Advances in Chemical Engineering and Science, 4(4), 491-502. https://doi.org/10.4236/ aces.2014.44051

McKeown, L. (2003). Social relations and breath odour. International Journal of Dental Hygiene, 1(4), 213-217. https:// doi.org/10.1034/j.1601-5037.2003.00056.x

Natale, M., Entin, E., \& Jaffe, J. (1979). Vocal interruptions in dyadic communication as a function of speech and social anxiety. Journal of Personality and Social Psychology, 37(6), 856-878. https://doi.org/10.1037/0022-3514.37.6.865 
Nelson, A. A., Grahe, J. E., \& Ramseyer, F. (2016). Interacting in flow: An analysis of rapport-based behavior as optimal experience. SAGE Open, 4, 1-11. https://doi.org/10.1177/2158244016684173

Nettleton, S., \& Watson, J. (1998). The body in everyday life. Routledge.

Olguin Olguin, D., Gloor, P. A., \& Pentland, A. (2009). Capturing individual and group behavior with wearable sensors. Proceedings of the 2009 association for the advancement of artificial intelligence. Standford, CA: AIII.

Page, R. A., \& Balloun, J. L. (1978). The effect of voice volume on the perception of personality. Journal of Social Psychology, 105(1), 65-72. https://doi.org/10.1080/00224545.1978.9924091

Parker, J. N., Cardenas, E., Dorr, A. N., \& Hackett, E. J. (in press). Using sociometers to advance small group research. Sociological Methods \& Research. https://doi.org/10.1177/0049124118769091

Pentland, A. (2008). Honest signals: How they shape our world. MIT Press.

Ramseyer, F., \& Tschacher, W. (2011). Nonverbal synchrony in psychotherapy: Coordinated body movement reflects relationship quality and outcome. Journal of Consulting and Clinical Psychology, 79(3), 284-295. https://doi.org/10.1037/ a0023419

Roberts, S. C., Little, A. C., Lyndon, A., Roberts, J., Havlicek, J., \& Wright, R. L. (2009). Manipulation of body odour alters men's self-confidence and judgements of their visual attractiveness by women. International Journal of Cosmetic Science, 31(1), 47-54. https://doi.org/10.1111/j.1468-2494.2008.00477.x

Sagioglou, D., \& Greitemeyer, T. (2014). Bitter taste causes hostility. Personality and Social Psychology Bulletin, 40(12), 1589-1597. https://doi.org/10.1177/0146167214552792

Schaller, M., \& Duncan, L. A. (2007). The behavioral immune system: Its evolution and social psychological implications. In J. P. Forgas, M. G. Haselton, \& W. von Hippel (Eds.), Evolution and the social mind: Evolutionary psychology and social cognition (pp. 293-307). Psychology Press.

Schaller, M. (2008). Evolutionary bases of first impressions. In N. Ambady \& J. J. Skowronski (Eds.), pp. 15-34. First impressions. Guilford Press.

Schlenker, B. R., \& Weigold, M. F. (1992). Interpersonal processes involving impression regulation and management. Annual Review of Psychology, 43(1), 133-168. https://doi.org/10.1146/annurev.ps.43.020192.001025

Schnall, S., Benton, J., \& Harvey, S. (2008). With a clean conscience: Cleanliness reduces the severity of moral judgments. Psychological Science, 19(12), 1219-1222. https://doi.org/10.1111/j.1467-9280.2008.02227.x

Sczesny, S., \& Stahlberg, D. (2002). The influence of gender-stereotyped perfumes on leadership attribution. European Journal of Social Psychology, 32(6), 815-828. https://doi.org/10.1002/ejsp.123

Snijders, T. A. B., \& Kenny, D. A. (1999). The social relations model for family data: A multilevel approach. Personal Relationships, 6(4), 471-486. https://doi.org/10.1111/j.1475.6811.1999.tb00204.x

Sorokowska, A. (2013). Seeing or smelling? Assessing personality on the basis of different stimuli. Personality and Individual Difference, 55(2), 175-179. https://doi.org/10.1016/j.paid.2013.02.026

Stel, M., Blascovich, J., McCall, C., Mastop, J., Van Baaren, R. B., \& Vonk, R. (2010). Mimicking disliked others: Effects of a priori liking on the mimicry-liking link. European Journal of Social Psychology, 40(5), 867-880. https://doi.org/10. 1002/ejsp. 655

Synnott, A. (1991). A sociology of smell. Canadian Review of Social Anthropology, 28(4), 437-459. https://doi.org/10. 1111/j.1755-618X.1991.tb00164.x

Taylor, P. J., (2013). How technology is revolutionizing our understanding of human cooperation (Inaugural lecture). Twente University Press. Retrieved April 11, 2020, from https://www.utwente.nl/en/academic-ceremonies/inaugurallectures/booklets-inaugural-lectures/2007-2014/Oratieboekje_Taylor.pdf

Tenney, E. R., Vazire, S., \& Mehl, M. R. (2013). This examined life: The upside of self-knowledge for interpersonal relationship. PLoS ONE, 8(7), e69605. https://doi.org/10.1371/journal.pone.0069605

Thornhill, R., \& Gangestad, S. W. (1999). The scent of symmetry: A human sex pheromone that signals fitness? Evolution and Human Behavior, 20(3), 175-201. https://doi.org/10.1016/S1090-5138(99)00005-7

Tickle-Degnen, L., \& Rosenthal, R. (1990). The nature of rapport and its nonverbal correlates. Psychological Inquiry, 1(4), 285-293. https://doi.org/10.1207/s15327965pli0104_1

Tomko, R. L., Brown, W. C., Tragesser, S. L., Wood, P. K., Mehl, M. R., \& Trull, T. J. (2012). Social context of anger in borderline personality disorders and depressive disorders: Findings from a naturalistic observations study. Journal of Personality Disorders, 28(3), 434-438. https://doi.org/10.1521/pedi_2012_26_064

Van Baaren, R., Janssen, L., Chartrand, T. L., \& Dijksterhuis, A. (2009). Where is the love? The social aspects of mimicry. Philosophical Transactions of the Royal Society B, 364(1528), 2381-2389. https://doi.org/10.1098/rstb.2009.0057

Van der Zee, S., Poppe, R., Taylor, P. J., \& Anderson, R. (2019). To freeze or not to freeze: A culture-sensitive motion capture approach to detecting deceit. PLoS ONE, 14(4), e0215000. https://doi.org/10.1371/journal.pone.0215000

Xu, H., Bègue, L., \& Busman, B. J. (2014). Washing the guilt away: Effects of personal versus vicarious cleansing on guilty feelings and prosocial behavior. Frontiers in Human Neuroscience, 8, 97. https://doi.org/10.3389/fnhum.2014.00097

Yano, K., Ara, K., Moriwaki, N., \& Kuriyama, H. (2009). Measurement of human behavior: Creating a society for discovering opportunities. Hitachi Review, 58, 139-144. http://citeseerx.ist.psu.edu/viewdoc/download? doi=10.1.1.497.4009\&rep $=$ rep $1 \&$ type $=$ pdf 